\title{
A clinical study of prevalence of gestational diabetes mellitus and associated risk factors at a tertiary care centre in Karnataka, India
}

\author{
Shridevi A. S., Prema Prabhudev*, Madhusoodana R. Bhovi
}

Department of Obstetrics \& Gynaecology, SS Institute of Medical sciences and Research Centre, Davangere, Karnataka, India

Received: 09 September 2015

Accepted: 13 October 2015

\section{*Correspondence:}

Dr. Shridevi A. S.,

E-mail: asshridevi@yahoo.com

Copyright: $\odot$ the author(s), publisher and licensee Medip Academy. This is an open-access article distributed under the terms of the Creative Commons Attribution Non-Commercial License, which permits unrestricted non-commercial use, distribution, and reproduction in any medium, provided the original work is properly cited.

\begin{abstract}
Background: Women with GDM are at increased risk for adverse obstetric and perinatal outcome .This study was undertaken to evaluate the prevalence of GDM using Diabetes in pregnancy study group India (DIPSI) criteria and associated risk factors in pregnant women.

Methods: Universal screening for GDM was done in 200 pregnant women with estimated gestational age between 14 -18 weeks. They were given $75 \mathrm{gm}$ oral glucose irrespective of meals. Diagnosis of GDM was made if $2 \mathrm{hr}$ plasma glucose was $\geq 140$, If plasma glucose is $<140$ then the test is repeated at $24-28$ weeks. If normal, then the test is repeated at 32 weeks. If plasma glucose is $<140 \mathrm{mg}$ at 32 weeks, then they are classified as non -GDM group. Prevalence of risk factors like age $\geq 25$, BMI $\geq 25$, family history of DM, bad obstetric history, history of GDM and macrosomia were studied in GDM and non GDM group and results are statistically analysed.

Results: The prevalence in this study was $11.5 \%$. The prevalence was more in women with advanced age, high BMI, positive family history of DM, past history of GDM and macrosomia.

Conclusions: The prevalence of GDM was found to be $11.5 \%$ and its association with risk factors found to be significant. DIPSI diagnostic procedure is a simple, cost effective and evidence based test.
\end{abstract}

Keywords: Gestational diabetes mellitus, Oral glucose tolerance test, Diabetes in pregnancy study group India

\section{INTRODUCTION}

Gestational diabetes mellitus (GDM) is a common metabolic abnormality during pregnancy which if untreated may lead to maternal and perinatal complications. Pregnancy is a complex endocrine metabolic adaptation and diabetogenic condition involving impaired cellular function and moderate elevation of blood glucose levels particularly following ingestion of the meal. ${ }^{1}$ Hormones like estrogen, progesterone, human placental lactogen, cortisone and growth hormones are antiinsulinogenic. These changes are increased in midpregnancy period and cause abnormal glucose tolerance in some woman rendering them prone for GDM.
GDM is defined as any degree of glucose intolerance with the onset or first recognition during pregnancy with or without remission after the end of pregnancy. ${ }^{2}$ The prevalence of diabetes is increasing globally and these numbers also includes women with GDM.GDM is important in that it poses a risk to the pregnant woman and her baby. Maternal complications of GDM are preeclampsia, polyhydramnios, elevated rates of operative delivery and preterm labor. GDM is associated with the higher incidence of Type 2 DM later in life. ${ }^{3}$ The major morbidities associated with infants of diabetic mothers include respiratory distress, macrosomia, polycythaemia, hypoglycaemia, hypocalcaemia and congenital malformations. Perinatal outcomes associated with poor glycemic control in mothers are associated with perinatal mortality as high as $42.9 \%{ }^{4}$ Appropriate 
diagnoses and management of GDM can improve maternal and perinatal outcome .These factors should alert the physician about the necessity to devote special attention to this segment of population especially in developing countries.

Prevalence rate of GDM vary widely by ethnicity. South Asian countries and Indian women have the highest frequency of GDM. The prevalence of GDM in India varies from $3.8 \%$ to $21 \%$ in different parts of the country depending on geographical locations and diagnostic methods used.

GDM has been found to be more prevalent in urban areas than in rural areas. ${ }^{5}$ In the random survey performed in various cities in India in 2002-03, an overall GDM prevalence of $16.55 \%$ was observed. ${ }^{6}$ In another study done in Tamilnadu, GDM was detected in $17.8 \%$ woman in urban, $13.8 \%$ in semi urban and $9.9 \%$ in rural areas. ${ }^{7}$ Priyanka Kalra et al found the prevalence of GDM to be $6.6 \%$ western Rajasthan women. ${ }^{8}$ Rajesh Rajput et al found the prevalence of GDM to be $7.1 \%$ in a tertiary care hospital in Haryana. ${ }^{9}$ Clinical risk factors for GDM are maternal age $\geq 30$,family history of $\mathrm{DM}$, previous history of GDM, obesity(BMI $\geq 27 \mathrm{~kg} / \mathrm{m} 2)$, previous history of macrosomia, previous history of unexplained fetal death and glycosuria. ${ }^{10}$

The data regarding prevalence of GDM and the number of women detected are important to allow for rational planning and allocation of resources and the preventive strategies that may be undertaken in future.

The Oral Glucose Tolerance Test (OGTT) is considered as gold standard for diagnosis of GDM. But it is a time consuming method, needs preparation of patient like 3 days normal diet prior to testing day, overnight fasting and repeated pricking. ${ }^{11}$ In the present study we have performed universal screening for GDM because compared to the selective screening universal screening detects more cases and improves maternal and neonatal prognosis. ${ }^{12}$ Universal screening for GDM is essential as it is generally accepted that women of Asian origin and especially ethnic Indians are at high risk of developing GDM and subsequent type 2 diabetes. ${ }^{13}$ In our study, the Diabetes in pregnancy study group, India (DIPSI) guidelines have been followed for screening of GDM.

A "single step procedure" was developed by Diabetes in pregnancy study group, India (DIPSI) due to technical difficulty of performing glucose tolerance test in fasting state as seldom pregnant women visiting antenatal clinic for the first time come in fasting state. ${ }^{2}$ If they are asked to come on another day in the fasting state many of them do not return. ${ }^{14}$ The DIPSI diagnostic criteria of $2 \mathrm{hr}$ plasma glucose $\geq 140 \mathrm{mg} / \mathrm{dl}$ after a $75 \mathrm{gm}$ glucose load irrespective of whether the woman is in fasting or nonfasting state is diagnostic of GDM and is a modified version of WHO guidelines in that WHO procedure requires woman to be in fasting state. ${ }^{2}$ The single step procedure has been approved by Ministry of Health, Government of India and also recommended by WHO. ${ }^{15}$ The present study was therefore undertaken to study the prevalence of GDM in pregnant woman attending a tertiary care hospital and associated risk factors.

The aim of the present study was to determine the prevalence of GDM in the antenatal woman attending SSIMS \& RC, Davangere, Karnataka, India using single step procedure of $75 \mathrm{gm}$ glucose load and to find the relation of GDM with various risk factors like maternal age, obesity, family history of GDM, previous h/o macrosomia, bad obstetric history and previous h/o GDM.

\section{METHODS}

The present study was conducted at the antenatal clinic in the Department of Obstetrics and Gynaecology at SSIMS \& RC, Davangere, Karnataka, India. A total of 200 pregnant women seeking antenatal care between 14-18 weeks gestation attending OPD or admitted as inpatients from December 2013 to December 2014 were enrolled for study.

This study was approved by institutional ethics committee and informed consent was taken from the women.

Inclusion criteria included pregnant women at 14-18 weeks of gestation irrespective of parity. All pregnant women with h/o DM prior to onset of pregnancy, major chronic diseases like carcinoma, tuberculosis, congestive cardiac failure, renal failure and liver failure were excluded from the study.

Detailed history and clinical examination of the enrolled women was carried out. A proforma containing general information like age, parity, socioeconomic status (according to Kuppuswamy classification), family history of DM in first degree relatives, past history of GDM and detailed past obstetric history was filled up for each women. BMI was calculated and BP was recorded. Selected women were subjected for DIPSI test. Women were given $75 \mathrm{gm}$ oral glucose dissolved in $200 \mathrm{ml}$ of water irrespective of their last meal timing. They were asked to drink it within 5 to 10 minutes, time was noted and women were asked to take rest for 2 hours during which they were asked to avoid physical activity. Venous blood sample was drawn at 2 hours and plasma glucose was estimated in the central laboratory by the glucose oxidise - peroxidise (GOD-DOD) method. ${ }^{16}$

\section{Diagnosis of GDM}

The criterion used was if the 2 hours venous plasma glucose measured after $75 \mathrm{gm}$ oral glucose load was $\geq 140$ $\mathrm{mg} / \mathrm{dl}$ (DIPSI criteria), the women was diagnosed as GDM. ${ }^{17}$ 
If the plasma glucose is $<140 \mathrm{mg} / \mathrm{dl}$ in the initial visit, she is advised to repeat the test at 24-28 weeks and if normal then again at 32 weeks.If plasma glucose is still less than $140 \mathrm{mg}$ at 32 weeks, they are classified as non -GDM group. Prevalence of risk factors for GDM like advanced age $>25$, BMI $>25$, family $\mathrm{h} / \mathrm{o} \mathrm{DM}$ in parents, bad obstetric history (h/o fetal loss after 20 week, unexplained perinatal loss, IUD), h/o macrosomia in previous pregnancy (B.W $>4000 \mathrm{gm})$ past h/o GDM were studied in GDM and non -GDM group and results were statistically analysed.

\section{Statistical analysis}

Results were expressed as numbers and percentages. Data collected was entered in Microsoft excel and analysed further using SPSS Software version 17 package. Statistical methods applied were descriptive statistics, chi - square test, 'P' valve $<0.05$ was considered statistically significant.

\section{RESULTS}

Table 1: Baseline characteristics of the study population.

\begin{tabular}{|c|c|c|}
\hline \multicolumn{2}{|c|}{ Characteristic } & $\begin{array}{l}\text { No of } \\
\text { participants }(n=200)\end{array}$ \\
\hline \multirow{4}{*}{$\begin{array}{l}\text { Age in } \\
\text { yrs }\end{array}$} & $16-20$ & $31(15.5 \%)$ \\
\hline & $21-25$ & $78(39 \%)$ \\
\hline & $26-30$ & $60(30 \%)$ \\
\hline & $>30$ & $31(15.5 \%)$ \\
\hline \multirow{3}{*}{$\begin{array}{l}\mathrm{BMI} \\
\left(\mathrm{kg} / \mathrm{m}^{2}\right)\end{array}$} & $<18.5$ & $52(26 \%)$ \\
\hline & $18.5-24.9$ & $86(43 \%)$ \\
\hline & $\geq 25$ & $62(31 \%)$ \\
\hline \multirow{4}{*}{ Parity } & Primi & $81(40.5 \%)$ \\
\hline & $2^{\text {nd }}$ Gravida & $75(37.5 \%)$ \\
\hline & $3^{\text {rd }}$ Gravida & $29(14.5 \%)$ \\
\hline & $\begin{array}{l}\text { 4th Gravida and } \\
\text { more }\end{array}$ & $15(7.5)$ \\
\hline \multirow{5}{*}{ Class } & Upper Class & $9(4.5 \%)$ \\
\hline & Upper middle & $41(20.5 \%)$ \\
\hline & Lower middle & $75(37.5 \%)$ \\
\hline & Upper lower & $72(36 \%)$ \\
\hline & Lower & $3(1.5 \%)$ \\
\hline
\end{tabular}

A total of 200 subjects were evaluated for GDM using the DIPSI criteria and there baseline characteristics are shown in table 1 . Out of 200 subjects, 23 were diagnosed as GDM. So the prevalence in our study was $11.5 \%$. The remaining $177(88.5 \%)$ had normal glucose tolerance and were classified as non - GDM group. There was a significant relationship between GDM and its risk factors. Most of the participants were below 26 years of age (109, $54.5 \%)$ and highest number of participants were in the age group $21-25$ years $(78,39 \%)$.
Table 2: Comparison of age distribution of GDM and non - GDM.

\begin{tabular}{|lll|}
\hline Age group & GDM $(\mathbf{n}=23)$ & Non - GDM $(\mathbf{n}=177)$ \\
\hline$<25$ Years & $6(26.08 \%)$ & $103(58.19 \%)$ \\
\hline$>25$ Years & $17(73.91 \%)$ & $74(41.80 \%)$ \\
\hline
\end{tabular}

$\mathrm{P}$ Value $=0.00363$

Table 2 shows age in relation with GDM. Among women with GDM, there were $17(73.91 \%)$ women who were aged more than 25 years compared to 74 (41.80\%) women without GDM and this observation was found to be statistically significant $(\mathrm{P}$ value $<0.05)$.

Table 3: BMI distribution of study population.

\begin{tabular}{|lll|}
\hline Age group & GDM $(\mathbf{n}=23)$ & Non - GDM $(\mathbf{n}=177)$ \\
\hline$<25$ Years & $6(26.08 \%)$ & $132(74.57 \%)$ \\
\hline$>25$ Years & $17(73.91 \%)$ & $45(25.42 \%)$ \\
\hline
\end{tabular}

$\mathrm{P}$ Value $=0.0001$

A significant association was found between prevalence of GDM and increasing BMI of participants $(\mathrm{P}<0.001)$.

Table 3 shows BMI distributions of study population. 17 (73.91\%) with BMI > 25 had GDM compared to 45 women $(25.42 \%)$ who had non - GDM though there BMI was more than 25 .

Table 4: Family h/o DM in study population.

\begin{tabular}{|ll|l|}
\hline Family history & GDM & GDM \\
\hline Present & $14(60.86 \%)$ & $44(24.85 \%)$ \\
\hline Absent & $9(39.13 \%)$ & $133(75.14 \%)$ \\
\hline P Value $=0.0001$ & & \\
\hline
\end{tabular}

Our study showed that prevalence of GDM was more amongst subjects with a family history of diabetes. As shown in Table 4, family history was present in 14 $(60.86 \%)$ women with GDM and ( $\mathrm{P}$ value $<0.0001)$. This observation was found to be statistically significant.

Table 5: Prevalence of GDM according to past obstetric history.

\begin{tabular}{|llll|}
\hline & $\begin{array}{l}\text { GDM } \\
(\mathbf{n}=23)\end{array}$ & $\begin{array}{l}\text { Non } \\
\text { GDM } \\
(\mathbf{n = 1 7 7 )})\end{array}$ & P value \\
\hline BOH & $9(39.13 \%)$ & $\begin{array}{l}11 \\
(6.21 \%)\end{array}$ & $<0.0001$ \\
\hline $\begin{array}{l}\text { H/o } \\
\text { macrosomia }\end{array}$ & $8(34.78 \%)$ & $7(3.95 \%)$ & $<0.0001$ \\
\hline Past h/o GDM & $10(43.47)$ & $8(4.51 \%)$ & $<0.0001$ \\
\hline
\end{tabular}

As shown in Table 5, BOH (h/o fetal less after 20 weeks, unexplained loss, IUD), h/o macrosomia (B.wt > $4000 \mathrm{gm}$ ) and past h/o GDM were more common in GDM population compared to non - GDM group. 
$\mathrm{P}$ value for $\mathrm{BOH}, \mathrm{h} / \mathrm{o}$ macrosomia and past h/o GDM is < 0.0001 which were statistically significant observations. Among 23 women with GDM, 17 were found to have GDM in first visit (14 - 18 weeks) and 8 were diagnosed with GDM in subsequent visits.

\section{DISCUSSION}

Gestational diabetes mellitus forms the most common medical complication of pregnancy. The women with GDM are at a higher risk for numerous maternal complications and their infants are at a higher risk for death and morbidity. There is general consensus that the prevalence of GDM is increasing globally. GDM prevalence has been reported to vary from $1.4 \%$ to $14 \%$ worldwide and differently among rural and ethnic groups. The prevalence is higher among Blacks, Latino, Native Americans and Asian woman than in White women. ${ }^{18,19}$ Ethnically, Indian subcontinent women have high prevalence of GDM and the relative risk of developing GDM is 11.3 times more compared to White women. ${ }^{20}$ Few studies conducted in India have shown increasing trends in prevalence from $2 \%$ in $1982,7.62 \%$ in 1991 to $16.55 \%$ in 2001 , hence necessitating universal screening for GDM in India. ${ }^{6,20-22}$ The universal screening for GDM detects more cases and improves maternal and offspring prognosis compared to selective screening. ${ }^{12}$ The universal screening appears to be most reliable and desired method for the detection of GDM, particularly in those populations at high risk for GDM.

For universal screening, the test should be simple and cost effective. The 2 step procedure of screening with $50 \mathrm{gm}$ glucose challenge test (GCT) and then diagnosing GDM based on oral glucose tolerance Test (OGTT) is not feasible is a country like India, because the pregnant women may have to visit the antenatal clinic twice and at least 3-5 blood samples have to be drawn which they resent and moreover "no show" rate is high. ${ }^{6,23,24}$ In light of these issues, the role of a single step test for screening and diagnosis of GDM using $75 \mathrm{gm}$ glucose load irrespective of last meal gains importance. DIPSI guidelines facilitate both economical and feasible mode of evaluation and it's a single step procedure which serves both as screening and diagnostic tool where a two hour plasma glucose of $\geq 140 \mathrm{mg} / \mathrm{dl}$ after 75 gm glucose is diagnostic of GDM. ${ }^{17}$

The recent concept is that the ideal period to screen for glucose intolerance is around 16 weeks of gestation as the fetal beta cell recognizes and responds to maternal glycemic levels as early as $16^{\text {th }}$ week of gestation. ${ }^{25}$ If found negative at this time, screening has to performed at around $24-28^{\text {th }}$ week and finally $32-34^{\text {th }}$ week. ${ }^{26,27}$

In this study, we have screened 200 pregnant women for GDM using DIPSI guidelines. We have examined the prevalence at GDM and its associated factors. This work provides baseline information about the prevalence and determinants of GDM, which could potentially help to incorporate early intervention measures.

The prevalence of GDM in our study sample was $11.5 \%$. None of them was a known case of diabetes. The prevalence of GDM in our study was similar to that reported by Seshiah $\mathrm{V}$ et al in Bangalore (12\%). ${ }^{6}$ However in a random survey preformed in various cities in India in 2002-2003, showed that prevalence was $16.2 \%$ in Chennai, $15 \%$ in Thiravanthapuram, $21 \%$ in Alwaye, $12 \%$ in Bangalore, $18.8 \%$ in Erode and $17.5 \%$ in Ludhiana. ${ }^{6}$

Established risk factors for GDM are advanced maternal age, obesity and family history of diabetes. ${ }^{10}$ In our study prevalence of GDM increased significantly with advanced maternal age. Among women with GDM, there were $17(73.91 \%)$ women who were aged more than $25 y$ rs compared to $74(41.80 \%)$ women without GDM. This is because of age related metabolic changes. A similar association of GDM and advanced age has been reported by Seshaiah et al. ${ }^{7}$

Obesity is an important risk factor in the development of GDM. ${ }^{7}$ In our study GDM was found to be significantly higher in women with higher BMI. This is supported by several studies finding that overweight or obesity at the start of pregnancy predisposes to $\mathrm{GDM}^{7}$ Gomez et al found that $25 \%$ to $50 \%$ of women with GDM had obesity. $^{28}$

In our study, a significantly higher percentage of women with GDM had positive family history of DM $(60.86 \%)$. Family history of DM has been reported to be associated with higher chances of developing GDM. ${ }^{29}$

A significant association between history of GDM in previous pregnancy and development of GDM in index pregnancy was seen in present study.

In our study a significantly higher percentage of women with GDM had bad obstetric history.9 (39.13\%) women with GDM had BOH compared to $11(6.21 \%$ ) in nonGDM group which is statistically significant. Kalra et al showed that $15.15 \%$ of GDM mothers had history of previous perinatal losses. ${ }^{8}$

In our study, $34.78 \%$ of women with GDM had a previous macrosomic babies (Body wt >4000 gm) comparable to study done by K. Sreekanthan et al which showed that $58.33 \%$ of GDM women had h/o previous large birth weight babies. ${ }^{30}$

The most common risk factors observed in the studied women with GDM were advanced maternal age, high BMI $\geq 25$, positive family history of diabetes and past $h / o$ GDM. A significant proportion of women with GDM also had past h/o fetal losses and macrosomic babies. Out of the six risk factors observed in current study, obesity is a modifiable risk factor. 


\section{CONCLUSIONS}

The prevalence of GDM is $11.5 \%$ in the present study and there is a greater prevalence of GDM in women with advanced age, obesity, family h/o DM and past h/o GDM. Among the South Asian countries, Indian women have highest frequency of GDM. Hence there is a need of universal screening to diagnose GDM to prevent both maternal and fetal complications. DIPSI diagnostic procedure is a simple, cost-effective and evidence based and has the potential to be a uniform testing approach in diagnosing. It causes least disturbance in a pregnant woman's routine activities and serves as both a screening and diagnostic procedure. The increased trend of GDM in India has become a potential public problem. Timely action should be taken to screen all pregnant women for glucose intolerance so that poor outcome of pregnancy can be reduced. It has been observed that BMI is a risk factor for GDM which is modifiable. GDM women have high risk of developing overt diabetes in future. They are the ideal group to be targeted for lifestyle modification or pharmacologic intervention in order to delay or postpone the onset of overt diabetes.

\section{Funding: No funding sources}

Conflict of interest: None declared

Ethical approval: The study was approved by the Institutional Ethics Committee

\section{REFERENCES}

1. Ghio A, Seghieri G, Lencioni C, Anichini R, Bertolotto A, De Bellis A, et al. 1- hour OGTT plasma glucose as a marker of progressive deterioration of insulin secretion and action in pregnant women. International Journal of Endocrinology. 2012; Article ID 460509:5 pages.

2. Seshiah V, Das AK, Balaji V, Joshi SR, Parikh MN, Gupta S. Diabetes in Pregnancy Study Group. Gestational diabetes mellitus guidelines. J Assoc Physicians India. 2006;54:622-8.

3. Davey RX, Hamblin PS. Selective versus universal screening for gestational diabetes mellitus: An evaluation of predictive risk factors. Med J Aust. 2001;174:118-21.

4. Otolorin EO, Famuyiwa OO, Bella AF, Dawodu AH, Adelusi B. Reproductive performance following active management of diabetic pregnancies at the university college hospital, Ibadan, Nigeria. Afr J Med Med Sci. 1985;14:155-60.

5. Seshiah V, Sahay BK, Das AK, Shah S, Banerjee S, Rao PV, et al. Gestational diabetes mellitus-Indian guidelines. J Indian Med Assoc. 2009;107:799802,804-06.

6. Seshiah V, Balaji V, Balaji MS, Sanjeevi CB, Green A. Gestational diabetes mellitus in India. J Assoc Phys India. 2004;52:707-11.

7. Seshiah V, Balaji V, Balaji MS. Prevalence of gestational diabetes mellitus in south India (Tamil
Nadu) - a community based study. J Assoc Physicians India. 2008;56:329-33.

8. Kalra P, Kachhwaha CP, Singh HV. Prevalence of gestational diabetes mellitus and its outcome in western Rajasthan. Indian $\mathbf{J}$ Endocr Metab. 2013;17:677-80.

9. Rajesh R, Yogesh Y, Smiti N, Meena R. Prevalence of gestational diabetes mellitus and associated risk factors at a tertiary care hospital in Haryana- Indian $\mathbf{J}$ Med Res. 2013:728-33.

10. Jovanovic L, Pettitt DJ. Gestational diabetes mellitus. JAMA. 2001;286:2516-8.

11. Shrestha A, Chawla CD. The glucose challenge test for screening of gestational diabetes. Katmandu Univ Med J. 2011;34(2):22-6.

12. Cosson E. Screening and insulin sensitivity in gestational diabetes. Abstract volume of the 40th Annual Meeting of the EASD. 2004:A350.

13. Dornhorst A, Paterson CM, Nicholls JS. High prevalence of gestational diabetes in women from ethnic minority groups. Diabet Med. 1992;9(9):53953.

14. O’Sullivan JB, Mahan CM. Criteria for oral glucose tolerance in pregnancy. Diabetes. 1964;13:278-85.

15. Government of India, Ministry of Health and Family welfare, Nirman Bhavan, New Delhi (DO no. M12015/93/2011-MCH/2011).

16. John A. Lott and Kathie Turner. Evaluation of Trinder's glucose oxidase method for measuring glucose in serum and urine. Clinical Biochemistry, Penguin books. 1975:1754-60.

17. Anjalakshi C, Balaji V, Balaji MS, Ashalatha S, Suganthi S, Arthi T, et al. A single test procedure to diagnose gestational diabetes mellitus, Acta Diabetol. 2009;46:51-4.

18. Hanna FW, Peter SJR. Screening of gestational diabetes: Past, present and future. Diabet Med. 2002;19:351-8.

19. American Diabetes Association. Gestational diabetes mellitus. Diabetic care. 2003;27:88-90.

20. Seshiah V, Balaji V, Madhuri S Balaji, Aruna Sekar, Sanjeevi CB, Anders Green One step procedure for screening and diagnosisof gestational diabetes mellitus. J Obstet Gynecol Ind. 2005;55:525-29.

21. Agrawal S, Gupta AN. Gestational Diabetes. J Association Physicians of India. 1982;30:203.

22. Narendra J, Muni Choodeppa C, Gurudas A, Ramprasad AV, Medha VT, Vijalakashmi N, et al. Prevalence of glucose intolerance during pregnancy. Int J Diabetes Dev Ctries. 1991;11:2-4.

23. Magee S, Walden CE, Benedetti TJ, Knopp RH. Influence of diagnostic criteria on the incidence of gestational diabetes and perinatal morbidity. JAMA. 1993;269:609-15.

24. de Aguiar LG, de Matos HJ, Gomes MB. Could fasting plasma glucose be used for screening highrisk outpatients for gestational diabetes mellitus? Diabetes Care. 2001;24:954-5. 
25. Nahum GG, Wilson SB, Stanislaw H. Earlypregnancy glucose screening for gestational diabetes mellitus. J Reprod Med. 2002;47:656-62.

26. Seshiah V, Balaji V, Balaji MS, Panneerselvam A. Early screening for gestational diabetes. Diabetes. 2006;55(suppl 1):2619-PO.

27. Jovanovic L, Peterson CM. Screening for gestational diabetes. Optimum timing and criteria for retesting. Diabetes. 1985;34(Suppl 2):21-3.

28. Gómez HL, Martínez ML, Rodríguez ZM. Clinical and epidemiological profile of diabetes mellitus in pregnancy, Isle of youth, 2008. MEDICC Rev. 2011;13:29-34.

29. Kim C, Lui T, Val dez R, Beckles GL. Does frank diabetes in first degree relatives of a pregnant woman affect the likely hood of her developing gestational diabetes or non-gestational diabetes? Am J Obstet Gynecol. 2009;201:576,ei-6.

30. Shreekanthan K, Belicita A, Rajendran K, Vijayakumar A. Prevalence of Gestational diabetes mellitus in a medical college in South India:A pilot study. Indian Journal of Clinical Practice. 2014;25(4):342-7.

Cite this article as: Shridevi AS, Prabhudev P, Bhovi MR. A clinical study of prevalence of gestational diabetes mellitus and associated risk factors at a tertiary care centre in Karnataka, India. Int J Reprod Contracept Obstet Gynecol 2015;4:1840-5. 